\title{
Gender Differences in Risk Factors of Ischemic Stroke Patients in a Tertiary Care Centre in North India
}

\author{
Ajay Kumar ${ }^{1}$, Ejaz Ahmed Shams², Sudhir Yadav ${ }^{3}$ \\ ${ }^{1}$ Department of Medicine, BRD Medical College, Gorakhpur, Uttar Pradesh, India. \\ ${ }^{2}$ Department of Medicine, BRD Medical College, Gorakhpur, Uttar Pradesh, India. \\ ${ }^{3}$ Department of Medicine, BRD Medical College, Gorakhpur, Uttar Pradesh, India.
}

\section{ABSTRACT}

\section{BACKGROUND}

Every year, more than 33 million people worldwide experience an acute stroke. ischemic stroke is caused by loss of blood supply to brain tissues due to sudden occlusion of arterial system by an embolus or a thrombus. Non-modifiable risk factors are age, sex \& genetic factors whereas modifiable ones include hypertension, diabetes, smoking, tobacco chewing, dyslipidaemia, obesity, cardiac disease etc. Aim of the present study is to evaluate \& compare the presence of various risk factors of ischemic stroke among males \& females.

\section{METHODS}

The study was conducted at BRD Medical College, Gorakhpur, during the academic year 2019-2020. All patients with ischemic stroke on CT Head \& age >18 years were included in this cross-sectional study. Detailed history including age, addictions, comorbidities (diabetes, hypertension), previous stroke history \& compliance to treatment was taken. A short neurological \& laboratory examination was performed in each patient.

\section{RESULTS}

In this study, a total of 100 patients was included out of which 57 were male \& 43 were female. The mean age of stroke was 64.82 years [males-65.62 years, females63.5 years]. The most common risk factors responsible for ischemic stroke was hypertension- 52\% [males- 50.4\%, females- 53.57\%]. Other risk factors were diabetes- 28\% [males- 29\%, females- 25.6\%], cardiac disease-13\% [males-8.8\%, females-18.6\%], dyslipidaemia- $12.3 \%$ in males \& none of females. Smoking \& tobacco chewing were more common among males (54.4\% each). Dyslipidaemia \& tobacco use was significantly associated with ischemic stroke in male patients.

\section{CONCLUSIONS}

There is increasing incidence of acute ischemic stroke which is directly related to modifiable risk factors like dyslipidaemia, smoking \& tobacco use in male patients. Advanced age is strongly related to acute stroke in both males \& females. Hypertension is the commonest risk factor overall for ischemic stroke.

\section{KEY WORDS}

Stroke, Dyslipidaemia, Ischemic, Hypertension, Diabetes

\author{
Corresponding Author: \\ Ejaz Ahmed Shams, \\ Room No. 48, New Married Hostel, \\ BRD Medical College Campus, \\ Gorakhpur, Uttar Pradesh, India. \\ E-mail:ejazshams@gmail.com
}

DOI: $10.14260 / j e m d s / 2020 / 358$

Financial or Other Competing Interests: None.

How to Cite This Article:

Kumar A, Shams EA, Yadav S. Gender differences in risk factors of ischemic stroke patients in a tertiary care centre in North India. J. Evolution Med. Dent. Sci. 2020;9(21):1633-1636, DOI:
Submission 16-02-2020,

Peer Review 04-05-2020,

Acceptance 11-05-2020,

Published 25-05-2020. 


\section{BACKGROUND}

Stroke affects 33 million individuals worldwide every year. ${ }^{1}$ According to 2012 data, stroke remained the third leading cause of death \& also the third leading cause of DALY (Disability Adjusted Life Years) lost due to premature mortality. ${ }^{2}$ Differences between men \& women in relation to stroke are increasingly being recognized. The difference in physiology between males \& females may underlie some of the variations in gender seen in stroke. WHO defines Stroke as "The Rapid development of clinical signs \& symptoms of a focal neurological disturbance lasting for more than 24 hours or leading to death with no apparent cause other than vascular origin." 3 When the focal neurological deficits last only for a short period of time (usually less than an hour), this is called a transient ischemic attack (TIA). Stroke may be due to ischemia or haemorrhage. ischemic stroke can be further divided into what have been referred to as etiologic subtypes, or categories thought to represent the causes of the stroke: cardioembolic, atherosclerotic, lacunar, other specific causes (dissections, vasculitis, specific genetic disorders, others) and strokes of unknown cause. Occurrence of stroke leads to a lot of physical disability and also cognitive and behavioural impairment.

Ischemic Stroke is caused by loss of blood supply to brain tissues due to sudden occlusion of arterial system. The occlusion may be due to emboli or thrombus. ischemic stroke is responsible for around $50-85 \%$ of all strokes worldwide. ${ }^{4}$ Stroke in women is a growing public health concern. Women have a higher lifetime risk of stroke, ${ }^{5}$ are more likely to experience recurrent stroke \& also a higher post stroke mortality, rate of disability, depression \& dementia compared to men.-9 This has been attributed to their highest life expectancy, consistent with the fact that age is the strongest independent risk factor for stroke $\&$ also a negative predictor for clinical outcome ${ }^{5}$. Cohort studies indicate that women \& men have differences in risk factor profiles, ${ }^{9-11}$ acute stroke presentation ${ }^{10-12} \&$ stroke aetiology. ${ }^{13}$ Recent research has also suggested that, among first-ever stroke patients, women are more frequently older, are more likely to have hypertension, atrial fibrillation and cardioembolic infarction, and experience reduced mortality and length of hospitalization. ${ }^{14}$

Non modifiable risk factors for stroke include Age, Sex \& genetic factors. The modifiable risk factors for ischemic stroke include Systemic Hypertension, Smoking, Tobacco use, Diabetes, Dyslipidaemia, Alcoholism, and Obesity etc.

WHO World Health Report-2007 states that ${ }^{15}$

- In each year approximately 15 million people suffer stroke worldwide. Of these, one third die and another one third are permanently disabled.

- Uncontrolled hypertension contributes to over 12.7 million strokes worldwide.

- In developed countries, the incidence of stroke is declining -It is mainly due to efforts to lower blood pressure and less smoking. However, the overall rate of stroke remains high due to the aging of the population.

- In India, Stroke is potentially the most devastating consequence of vascular disease, causing serious long-term disability and incurring extremely high medical, emotional and financial costs.
Due to paucity of data studies concerning stroke patients in this region, this study has been done to evaluate the prevalence of various risk factors in males \& females presenting to a tertiary care center in Gorakhpur district.

\section{METHODS}

The present cross-sectional study was conducted in Dept. Of Medicine, BRD Medical College, Gorakhpur during the academic year from 2019-2020 after approval by the institutional ethical committee. The study was conducted among 100 adult patients (age>18 years) of ischemic stroke, both males \& females (sample size $=100$ ) admitted to Medicine Department. The sample size was taken based on the convenience of the study.

\section{Inclusion Criteria}

All patients of ischemic Stroke on CT Head \& age $>18$ years were considered for this study.

\section{Exclusion Criteria}

Patients with other forms of CVA like SAH/Posttraumatic/SDH/EDH \& CNS infections were not included. Patient or their attendants, who did not give consent were excluded from the study.

A brief history of each patient was taken regarding Age, $\mathrm{H} / \mathrm{O}$ Addictions - Smoking, Alcohol use (frequency/day \& no. of years), $\mathrm{H} / \mathrm{O}$ previous Cardiac illness or Coronary event, $\mathrm{H} / \mathrm{O}$ previous stroke, comorbidities like Systemic Hypertension \& Diabetes Mellitus \& compliance to treatment was taken. A short examination including general \& neurological examination was undertaken to assess the GCS, focal neurological deficit, cranial nerve involvement, Gait \& Speech abnormalities. BP, FBS \& PPBS was recorded for every patient. Weight \& Height was recorded. Various routine tests were performed on these patients including Complete Blood Count, Liver \& Renal function tests, Thyroid \& Lipid profiles, HbA1c, ESR, CRP, Urine-Routine/microscopy, HIV status \& ECG. Radiological imaging studies included CT Head or MRI Brain (if needed) \& 2D Echocardiography. Carotid Doppler was done in selected patients.

\section{Statistical Analysis}

The results were presented in frequencies \& percentages. The Chi-square test was used to compare categorical variables. The $\mathrm{p}$ value $<0.05$ was considered significant. All the analysis was carried out on SPSS 16.0 version.

\section{RESULTS}

A total of 100 patients -57 males \& 43 females were included in the study. The mean age of ischemic stroke overall was 64.82 years; in males it was 65.62 years while in females it was 63.5 years. More than one third (37\%) of patients were 
of 60-70 years of age, followed by 50-60 years (28\%), >70 years $(25 \%) \%,<50$ years $(10 \%)$. More than half of the patients were males. Advanced age itself is responsible for increased number of acute ischemic stroke in both male \& female patients. [Table 1]

\begin{tabular}{|ccccccc|}
\hline Age in & \multicolumn{2}{c}{ Male } & \multicolumn{2}{c}{ Female } & \multicolumn{2}{c|}{ Total } \\
Years & No. & $\mathbf{\%}$ & No. & $\mathbf{\%}$ & No. & $\mathbf{\%}$ \\
$<50$ & 6 & 60.0 & 4 & 40.0 & 10 & 10.0 \\
$50-60$ & 11 & 39.3 & 17 & 60.7 & 28 & 28.0 \\
$61-70$ & 26 & 70.3 & 11 & 29.7 & 37 & 37.0 \\
$>70$ & 14 & 56.0 & 11 & 44.0 & 25 & 25.0 \\
Total & $\mathbf{5 7}$ & $\mathbf{5 7 . 0}$ & $\mathbf{4 3}$ & $\mathbf{4 3 . 0}$ & $\mathbf{1 0 0}$ & $\mathbf{1 0 0 . 0}$ \\
\hline \multicolumn{2}{r|}{ Table 1. Age and Sex Distribution of Ischemic Stroke Patients } \\
\hline
\end{tabular}

Hypertension was most common among patients of age $61-70$ years $(56.8 \%)$ \& least common among $<50$ years $(40 \%)$. Tobacco consumption which was related to duration of use was found to be most common in age group $>70$ years.

Diabetes was most common among patients of age group 61-70 years. Stroke in patients with cardiac disease was more common among relatively younger patients $<50$ years $(20 \%)$. There was no significant association of risk factors of ischemic stroke with age. [Table 2]

\begin{tabular}{|c|c|c|c|c|c|c|c|c|c|c|c|}
\hline \multirow{3}{*}{$\begin{array}{c}\text { Risk } \\
\text { Factors }\end{array}$} & \multicolumn{8}{|c|}{ Age in Years } & \multirow{2}{*}{\multicolumn{2}{|c|}{ Total }} & \multirow{3}{*}{$\begin{array}{c}\text { P- } \\
\text { Value }\end{array}$} \\
\hline & \multicolumn{2}{|c|}{$\begin{array}{c}<50 \\
(n=10)\end{array}$} & \multicolumn{2}{|c|}{$\begin{array}{c}50-60 \\
(n=28)\end{array}$} & \multicolumn{2}{|c|}{$\begin{array}{c}61-70 \\
(n=37)\end{array}$} & \multicolumn{2}{|c|}{$\begin{array}{c}>70 \\
(n=25)\end{array}$} & & & \\
\hline & No. & $\%$ & No. & $\%$ & No. & $\%$ & No. & $\%$ & No. & $\%$ & \\
\hline Hypertension & 4 & 40.0 & 14 & 50.0 & 21 & 56.8 & 13 & 52.0 & 52 & 52.0 & 0.81 \\
\hline $\begin{array}{l}\text { Tobacco } \\
\text { chewing }\end{array}$ & 4 & 40.0 & 9 & 32.1 & 14 & 37.8 & 11 & 44.0 & 38 & 38.0 & 0.84 \\
\hline $\begin{array}{l}\text { Tobacco } \\
\text { smoking }\end{array}$ & 4 & 40.0 & 11 & 39.3 & 15 & 40.5 & 12 & 48.0 & 42 & 42.0 & 0.91 \\
\hline $\begin{array}{l}\text { Diabetes } \\
\text { mellitus }\end{array}$ & 2 & 20.0 & 8 & 28.6 & 13 & 35.1 & 5 & 20.0 & 28 & 28.0 & 0.56 \\
\hline Cardiac disease & 2 & 20.0 & 3 & 10.7 & 5 & 13.5 & 3 & 12.0 & 13 & 13.0 & 0.89 \\
\hline Obesity & 2 & 20.0 & 2 & 7.1 & 4 & 10.8 & 2 & 8.0 & 10 & 10.0 & 0.35 \\
\hline Dyslipidaemia & 2 & 20.0 & 1 & 3.6 & 3 & 8.1 & 1 & 4.0 & 7 & 7.0 & 0.31 \\
\hline & & ble & scs & ciati & of & $\begin{array}{l}\text { isk } F \\
\text { ts } w\end{array}$ & 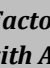 & $\begin{array}{l}\text { s of } \\
\text { ge }\end{array}$ & & & \\
\hline
\end{tabular}

Hypertension was slightly more common among female patients $(53.5 \%)$ than in males $(50.4 \%)$. Diabetes was more common among male patients $(29.8 \%)$ but for both Hypertension \& Diabetes, the difference among males \& females was not statistically significant ( $p>0.05)$. Smoking (54.4\%) \& Tobacco Chewing (54.4\%) was way more common among male subjects with significant association. Dyslipidaemia was recorded in 7 male patients \& none of female patients \& thus, the association seemed to be statistically significant. $(p=0.01)$ [Table 3]

\begin{tabular}{|cccccc|}
\hline \multirow{7}{*}{ Risk Factors } & Male (n=57) & \multicolumn{2}{c|}{ Female (n=43) } & P-Value ${ }^{\#}$ \\
& No. & \% & No. & \% & \\
Hypertension & 29 & 50.9 & 23 & 53.5 & 0.79 \\
Tobacco chewing & 31 & 54.4 & 7 & 16.3 & $0.0001^{*}$ \\
Tobacco smoking & 31 & 54.4 & 11 & 25.6 & $0.004^{*}$ \\
Diabetes mellitus & 17 & 29.8 & 11 & 25.6 & 0.64 \\
Cardiac disease & 5 & 8.8 & 8 & 18.6 & 0.14 \\
Obesity & 8 & 14.0 & 2 & 4.7 & 0.29 \\
Dyslipidaemia & 7 & 12.3 & 0 & 0.0 & $0.01^{*}$ \\
\hline \multicolumn{5}{c|}{ Table 3. Association of Risk Factors of } \\
Ischemic Stroke Patients with Sex \\
\hline Chi-square test\#, *Significant. The percentage of obese was higher among males \\
(8 out of 10) than females.
\end{tabular}

\section{DISCUSSION}

In this study, the mean age of stroke patients was 64.82 years, in males it was 65.62 years 63.5 years in females. Studies by Eapen et al $^{16}$ recorded mean age of stroke as 57 years while Naik et $\mathrm{al}^{17}$ recorded it as 58.27 years. Hypertension being the commonest risk factor was prevalent in $52 \%$ of patients, with similar prevalence among males \& females. Studies done by Naik et al, ${ }^{17}$ Kay Sin Tan et $\mathrm{al}^{18}$ had recorded $40.66 \%$ \& $42.6 \%$ patients as hypertensives. The studies conducted in India recorded less proportion of hypertensives as compared to western literature which may be attributed to lack of awareness among rural population regarding Hypertension screening \& regular checkup in adult patients.

In this study, $28 \%$ of stroke patients were diabetic, this proportion was $29.8 \%$ among males \& $25.6 \%$ among females. Statistical association with gender with respect to Hypertension \& Diabetes was insignificant. Framingham Cohort Study ${ }^{19}$ suggested that diabetic women had 3.5 times higher risk for stroke compared to non-diabetic women whereas diabetic men had 2.1 times the same risk. There was a clear cut predilection of Tobacco consumption among male patients which was statistically significant both in relation to Smoking $(p=0.004)$ \& Tobacco Chewing $(p=0.0001)$. Our study correlates with Donnan et $\mathrm{al}^{20}$ where smoking was one of the strongest risk factors for ischemic stroke. Meta-analysis done by Shinton $\mathrm{R}$ et $\mathrm{al}^{21}$ observed the same results.

Dyslipidaemia as a risk factor was present only in 7 males with significant association among males $(\mathrm{p}=0.01)$. Prior study done by Eapen et al showed $17 \%$ of patients with dyslipidaemia in stroke. Association of ischemic stroke with presence of Cardiac disease was more prevalent among females $(18.6 \%)$ than males $(8.8 \%)$. The cardiac diseases included Rheumatic Heart Disease with Mitral Stenosis, Dilated Cardiomyopathy \& Severe LV Dysfunction. Rheumatic Mitral Stenosis was the most common cardiac disease leading to ischemic stroke (38.5\%, 5 out of 13 patients). Obesity was more common among males (14.7\%) than females $(4.7 \%)$. Difference between males \& females in the predictors of overall risk of ischemic stroke are of growing importance. Given that women have a higher lifetime risk for stroke \& account for more than half of all stroke deaths, genderspecific factors merit investigation \& may help to target public health interventions.

\section{CONCLUSIONS}

Men \& women differ in their risk with respect to various predictors of ischemic stroke including age, hypertension, diabetes, cardiac disease, hormonal changes, tobacco \& alcohol use, dyslipidaemia, obesity \& others. In this study, there exists a significant statistical association between dyslipidaemia, smoking \& tobacco chewing with male sex in patients of ischemic stroke. Further research is warranted in each of these areas to better understand the complexities of the effect of sex on ischemic stroke risk, aetiology \& progression. 


\section{REFERENCES}

[1] Mozaffarian D, Benjamin EJ, Go AS, et al. Executive summary: heart disease and stroke statistics - 2015 update: a report from the American Heart Association. Circulation 2015;131(4):434-41.

[2] World Health Organization. World Health Statistics 2014. Geneva: WHO, 2014.

[3] Sacco RL, Kasner SE, Broderick JP, et al. An updated definition of stroke for the 21st century: a statement for healthcare professionals from the American Heart Association/American Stroke Association. Stroke 2013;44(7):2064-89.

[4] Feigin VL, Lawes CMM, Bennet DA, et al. Worldwide stroke incidence and early case fatality in 56 population based studies: a systematic review. Lancet Neurology 2009;8(4):355-69.

[5] Seshadri S, Beiser A, Kelly-Hayes M, et al. The lifetime risk of stroke: estimates from the Framingham Study. Stroke 2006;37(2):345-50.

[6] Bousser MG. Stroke in women: the 1997 Paul Dudley White International Lecture. Circulation 1999;99(4):463-7.

[7] Kapral MK, Fang J, Hill MD, et al. Sex differences in stroke care and outcomes: results from the Registry of the Canadian Stroke Network. Stroke 2005;36(4):809-14.

[8] Niewada M, Kobayashi A, Sandercock PAG, et al. Influence of gender on baseline features and clinical outcomes among 17,370 patients with confirmed ischemic stroke in the International Stroke Trial. Neuroepidemiology 2005;24(3):123-8.

[9] Holroyd-Leduc JM, Kapral MK, Austin PC, et al. Sex differences and similarities in the management and outcome of stroke patients. Stroke 2000;31(8):1833-7.

[10] Roquer J, Campello AR, Gomis M. Sex differences in firstever acute stroke. Stroke 2003;34(7):1581-5.

[11] Di Carlo A, Lamassa M, Baldereschi M, et al. Sex differences in the clinical presentation, resource use, and 3-month outcome of acute stroke in Europe: data from a multicenter multinational hospital-based registry. Stroke 2003;34(5):1114-9.

[12] Labiche LA, Chan W, Saldin KR, et al. Sex and acute stroke presentation. Ann Emerg Med 2002;40(5):453-60.

[13] Kolominsky-Rabas PL, Weber M, Gefeller O, et al. Epidemiology of ischemic stroke subtypes according to TOAST criteria: incidence, recurrence and long-term survival in ischemic stroke subtypes: a population-based study. Stroke 2001;32(12):2735-40.

[14] Arboix A, Cartanyà $A$, Lowak $M$, et al. Gender differences and woman-specific trends in acute stroke: results from a hospital-based registry (1986-2009). Clin Neurol Neurosurg 2014;127:19-24.

[15] World Health Report - 2007, from the World Health Organization: International Cardiovascular Disease Statistics (2007 Update), American Heart Association Publisher.

[16] Eapen RP, Parikh JH, Patel NT. A study of clinical profile and risk factors in cerebrovascular stroke. Gujarat Medical Journal 2009;64(2):47-52.

[17] Naik M, Rauniyar RK, Sharma UK, et al. Clinicoradiological profile of stroke in eastern Nepal: a computed tomographic study. Kathmandu University of Medical Journal 2006;4(2):161-6.

[18] Tan KS, Navarro JC, Wong KS, et al. Clinical profile, risk factors and etiology of young ischemic stroke patients in Asia: a prospective multicentre, observational study in eight cities. Neurology Asia 2014;19(2):117-27.

[19] Franconi F, Campesi I, Occhioni S, et al. Sex-gender differences in diabetes vascular complications and treatment. Endocr Metab Immune Disord Drug Targets 2012;12(2):179-96.

[20] Donnan GA, McNeil JJ, Adena MA, et al. Smoking as a risk factor for cerebral ischemia. Lancet 1989;334(8664):643-7.

[21] Shinton R, Beevers G. Meta-analysis of relation between cigarette smoking and stroke. BMJ 1989;298(6676):78994. 